\title{
A GENE CONTROLLING MALE PHEROMONAL FACILITATION OF PMSG-INDUCED OVULATION IN MICE
}

\author{
B. E. ELEFTHERIOU, D. W. BAILEY AND M. X. ZARROW \\ The Fackson Laboratory, * Bar Harbor, Maine 04609, and \\ Department of Biobehavioral Sciences, The University of Connecticut, \\ Storrs, Connecticut 06268, U.S.A.
}

(Received 24th April 1972, accepted 5th May 1972)

During the course of studies on PMSG- and HCG-induced pheromonal facilitation of ovulation (Zarrow, Christenson \& Eleftheriou, 1971; Zarrow, Eleftheriou \& Denenberg, 1972), strain differences were noted in the response of the immature female mouse to both PMSG and HCG. Since strain differences have been reported previously for pheromonal block of pregnancy (Bruce, 1968), and it was postulated that this system existed as a single gene (Chapman \& Whitten, 1968), the following experiments were conducted to determine the heritability of the male pheromonal system involved in PMSG-induced facilitation of ovulation.

Female mice of the C57BL/6J and SWR/J strains were housed, one per cage, following weaning at 21 days of age. Lighting was kept on a $12 \mathrm{hr}$ on/12 hr off schedule (on at 06.00 , off at 18.00 hours). At 09.00 hours on the 24th day of age, each mouse was injected subcutaneously with 2 i.u. PMSG (Ayerst-Equinex). It had previously been shown that this dose of PMSG did not cause ovulation at $24 \mathrm{hr}$ in these strains of mice (Christenson \& Eleftheriou, 1972). At noon on the 2 nd day ( $51 \mathrm{hr}$ later), each female was transferred to a cage with a double wire partition. The female was housed on the side which the male had used previously and the male was transferred to the opposite side. All females were killed approximately $21 \mathrm{hr}$ later, i.e. 72 to $74 \mathrm{hr}$ after PMSG injection, and the oviducts were removed for examination under a dissecting microscope at $\times 40$ magnification. Ova were counted and the state of the ova, i.e. whether clumped, denuded, etc. (Zarrow, Caldwell, Hafez \& Pincus, 1958), was recorded.

Eighteen females of strain C57BL/6J were exposed to C57BL/6J males and another eighteen females were exposed to SWR/J males. Similarly, eighteen females of strain SWR/J were exposed to C57BL/6J and eighteen to SWR/J males. For controls, another eighteen females of each strain were injected with PMSG, and transferred to a clean cage but were not exposed to a male, while a further eighteen females were injected with saline alone and also were not exposed to males. In addition, eighteen females of each strain were exposed to

* The Jackson Laboratory is fully recognized by the American Association for Accreditation of Laboratory Animal Care. 


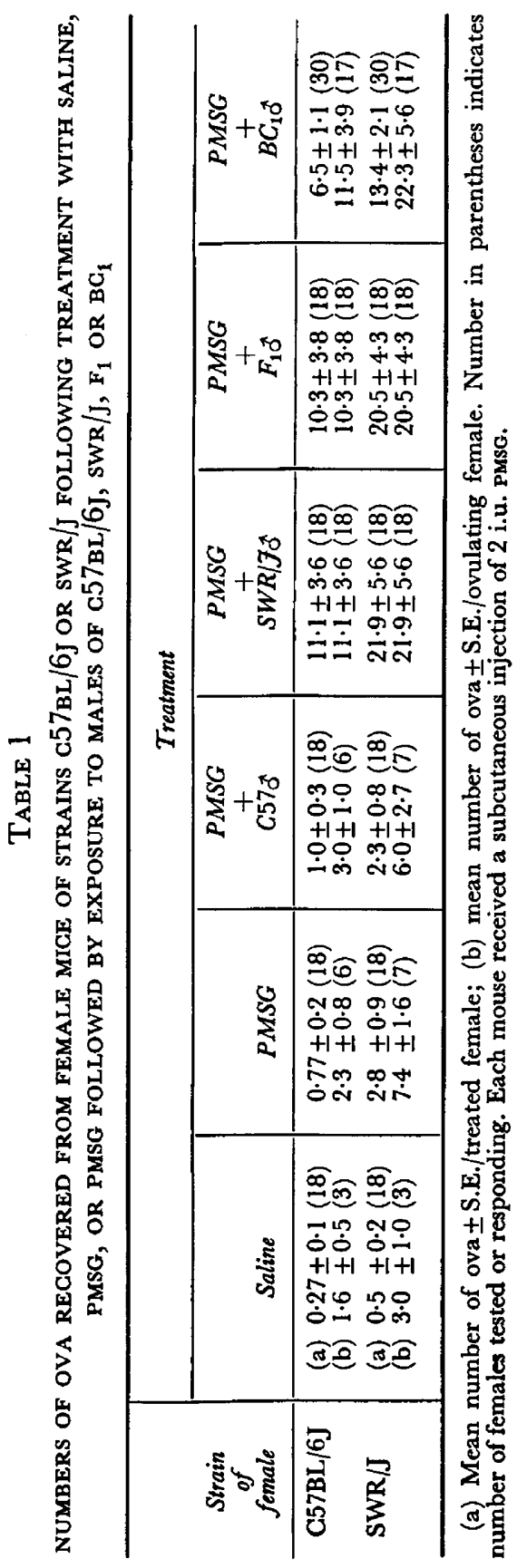


(C57BL/6J ㅇ $\times$ SWR/J $\left.\sigma^{7}\right) \mathrm{F}_{1}$ males and thirty females of each strain, C57BL/6J or SWR/J, were individually exposed to thirty different males of the backcross: $\left(\mathrm{C} 57 \mathrm{BL} / 6 \mathrm{~J}\right.$ o $\times \mathrm{SWR} / \mathrm{J}$ o $^{*}$ ) $\times \mathrm{C} 57 \mathrm{BL} / 6 \mathrm{~J} 0^{*}$. This entire experiment was conducted during the month of February 1972. This was possible since a number of pilot experiments had indicated the necessary genetic crosses to be made. Once males from these crosses were obtained, females were individually exposed in a random fashion to the various males.

Data were subjected to an analysis of variance after correction for regression on body weight. The data were analysed both in terms of ova per female and ova per ovulating female. $\chi^{2}$ tests of proportions of females that ovulated in backcross generations were used to test genetic hypotheses.

(o)

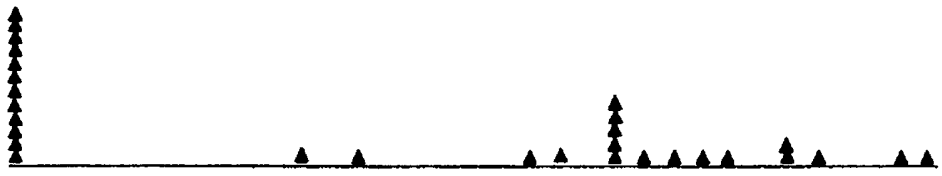

(b)
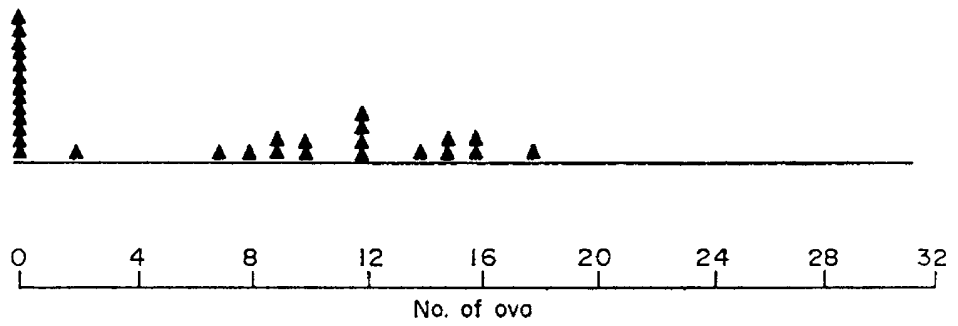

(0)

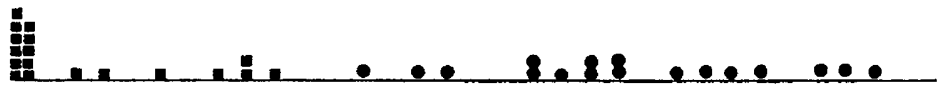

(b)

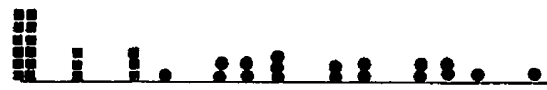

TEXT-FIG. 1. Frequency distribution of the number of ova counted in (a) SWR/J or (b) C57BL/6J females following the injection of 2 i.u. PMSG and exposure to C57BL/6J (-), SWR/J (๑) or $\mathrm{BC}_{1}(\Delta)$ males. The results for females of the C57BL/6J and SWR/J strains were combined for statistical analyses since there was no significant difference in the number of females from both strains responding to $\mathrm{BC}_{1}$ males.

The results are summarized in Table 1 and Text-fig. 1 . There was a significant increase in the number of ova shed after exposure of both C57BL/6J and SWR/J females to SWR/J males. Additionally, there was a significant difference in the number of ova shed by females of these two strains $(11.1 \pm 3.6$ for C57BL/6J and $21.9 \pm 5.6$ for SWR/J females). The difference confirms our previous findings regarding these two strains (Zarrow et al., 1971).

Exposure of either C57BL/6J or SWR/J females to G57BL/6J males did not result in significant enhancement of the number of ova shed, thus indicating a lack of facilitation by the male of this strain. By contrast, exposure to the $F_{1}$ males

$\mathbf{L}$ 
resulted in significant enhancement which was in close relationship to the facilitation occurring after exposure to SWR/J males.

Exposure of females of both strains to males of the backcross (C57BL/6 $\times$ $\mathrm{SWR} / \mathrm{J}) \times \mathrm{C} 57 \mathrm{BL} / 6 \mathrm{~J}$ resulted in thirty-four out of sixty males eliciting facilitation (see Text-fig. 1). Based on $\chi^{2}$ tests, these data (pooled) are statistically different $(P<0.01)$ from a $3: 1$ ratio but not from a $1: 1$ ratio. Thus, we conclude that this pheromone is probably controlled by a single gene. Furthermore, since the $(\mathrm{C} 57 \mathrm{BL} / 6 \mathrm{~J} \times \mathrm{SWR} / \mathrm{J}) \mathrm{F}_{1}$ males all elicited a positive response from both $\mathrm{C} 57 \mathrm{BL} / 6 \mathrm{~J}$ and $\mathrm{SWR} / \mathrm{J}$ females, the conclusion was reached that pheromone presence in the SWR/J males is determined by a single dominant gene. We propose the symbols $P h r^{h}$ and $P h r^{l}$ for the alleles that determine high and low (or no) pheromonal effect, respectively, in males of these strains.

Pregnancy blocking by the male was shown to be inherited recessively (Chapman \& Whitten, 1968), whereas ovulation facilitation by the male has been shown here to be inherited dominantly. This difference can be explained in at least two ways. Firstly, the male stimulus in the two instances may be controlled either by different alleles at one locus or by different genes at different loci, for different mouse strains were studied in the two instances. Secondly, if the amount of pheromone present in the $F_{1}$ hybrid male due to gene dosage is half the quantity that it is in the SWR male and, furthermore, is above the threshold required for facilitation of ovulation but below that required for pregnancy block, it would then be possible to account for the difference and still be dealing with the same gene.

Another difference is that Chapman \& Whitten (1968) suggested that one gene controlled both the response of the female and the stimulus of the male, whereas in the present case, although C57BL/6J females had a lower mean ova count, females of both strains were equally likely to respond, thereby indicating no genetic differences other than for number of ova shed per stimulated female. However, the pathways of pregnancy block and ovulation facilitation no doubt differ completely; therefore, it is not difficult to see that these two responses in females may not be controlled by the same gene(s).

This work was supported in part by Research Grant HD-05860 from the Institute of Child Health and Human Development; in part by Research Grant GM-15574 from the Institute of General Medical Sciences, and in part by Research Grant HD-04639 from the Institute of Child Health and Human Development.

\section{REFERENCES}

BRUCE, H. M. (1968) Absence of pregnancy block in mice when stud and test males belong to an inbred strain. F. Reprod. Fert. 17, 407.

Chapman, V. M. \& WhitTen, W. K. (1968) The occurrence and inheritance of pregnancy-block in inbred mice. Genetics, 61, Suppl. 59.

Christenson, C. M. \& Eleftheriou, B. E. (1972) Dose-dependence of superovulation response in mice to two injections of PMSG. F. Reprod. Fert. 29, 287.

Zarrow, M. X., Caldwell, A. L., Hafez, E. S. E. \& Pincus, G. (1958) Superovulation in the immature rat as a possible assay for LH and HCG. Endocrinology, 63, 748.

Zarrow, M. X., Christenson, C. M. \& Eleftheriou, B. E. (1971) Strain differences in the ovulatory response of immature mice to PMS and to the pheromonal facilitation of PMS-induced ovulation. Biol. Reprod. 4, 52.

Zarrow, M. X., Eleffheriou, B. E. \& Denenberg, V. H. (1972) Pheromonal facilitation of hcGinduced ovulation in different strains of immature mice. Biol. Reprod. 6, 277. 